\title{
Construction of Vocational Education Think Tank Based on Embeddedness Theory
}

\author{
Lu Zhu \\ Institute of Vocational and Continuing Education \\ Yunnan University \\ Kunming, Yunnan, China, 650000
}

\begin{abstract}
As an integral part of China's new style education think tank, the vocational education think tank plays a significant role in decision implementation, thoughts exchange, practice guidance, reform and innovation in vocational education. Based on the connotation and development of embeddedness theory, an embedded vocational education think tank model is constructed in this paper, enhancing the embedding of cognition, culture, environment, organization, relationship and other factors. Construction of vocational education think tank should be promoted in participant, exchange mechanism, funding resources, organizational form, dialogue between disciplines and other aspects.
\end{abstract}

Keywords-embeddedness; vocational education; education think tank; connection

\section{INTRODUCTION}

Embeddedness is interpreted as close implantation in $\mathrm{Ci}$ Hai[1], China's comprehensive dictionary, indicating an inclusion relation between two objects, especially enhancing the part and the whole and their interrelation. Embeddedness theory observes macro to micro relations among environment, organization, the bilateral and other factors, as well as implicit relations among relationship, culture, cognition and other factors, laying an important effect on promoting multi participants in the construction of vocational education and on remodeling cooperation among varied participants.

\section{CONNOTATION AND FRAMEWORK OF EMBEDDEDNESS} THEORY

\section{A. Connotation}

Embeddedness theory is an important branch of new economic sociology. The concept of embeddedness was first proposed in The Great Transformation in 1944 by Polanyi, who suggested that human's economic behaviors before 19th century were embedded in their social relations and the economy is a part of society [2]. Afterward, the connotation of embeddedness was further enriched by Granovetter, who expanded Polanyi's bilateral relation to the whole social network composed of politics, cultures, religions and other elements. Then based on Granovetter's research, embeddedness theory was applied in practice by numerous management researchers. And after three development phases, a complete theoretical system has been fully established.

\section{B. Framework}

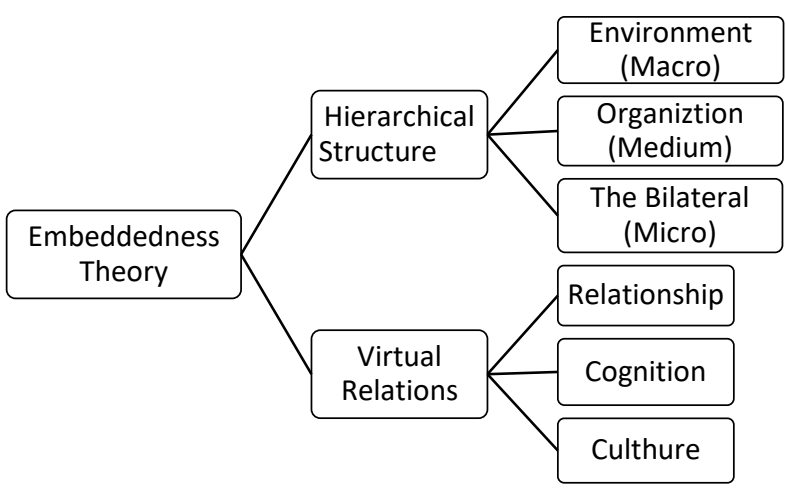

Fig. 1. The framework of embeddedness theory

As Fig. 1 Indicated, embeddedness theory suggests the hierarchical structure including environment, organization and the bilateral from macro to micro, as well as relations between substantive organizations and virtual patterns including relationship, cognition, culture and other factors.

\section{1) Environment embeddedness}

Environment embeddedness stresses the importance of the implantation of macro background since organizational behavior is affected by the social environment, which shows universality and totality. Two major elements of environment embedded are state and industry.

\section{2) Organization embeddedness}

Organization embeddedness emphasizes the mutual effect, interaction and restriction among multiple subjects from the intermediate perspective. Complicated social network exerts an influence on organizational behaviors, and organizations, driven by interests, would cooperate with each other. The efficiency of this cooperation can last in long duration, and show persistence.

\section{3) The bilateral embeddedness}

The bilateral embeddedness observes micro organization cooperation, advocating that trust and support should exist between two organizations. However, bilateral relationship maintaining largely decides the success or fail of multilateral 
cooperation and the establishment of multi-organization cooperative network.

\section{4) Relation embeddedness}

Relation embeddedness suggests the existence of universal relation among varied organization. The difference of content, intensity and duration of this relational network can lay effect of different level on organizational behavior. On the one side, it can create value for the organization, and on the other side, it might impede performance improvement.

\section{5) Cognition embeddedness}

Cognition embeddedness proposes that when making choice, the subject is affected by the surrounding environment and mind guidance or restriction. In a corporation, long-developed group cognition, acquiesced by the organization, will influence the strategic decision and implementation as well as the daily operation of the company [3].

\section{6) Culture embeddedness}

Culture embeddedness suggests the restriction and influence of traditional value, religion and belief, common faith, orthodox practice and other socio-cultural factors on organization's economic behavior [4]. As a visual pattern, culture lays diversified, unconscious, profound and lasting effect on the organization.

\section{ANALYSIS ON CONSTRUCTION OF VOCATIONAL EDUCATION THINK TANK BASED ON EMBEDDEDNESS THEORY}

Vocational education's particularity not only requires its think tank construction in the environment, organization, bilateral relation and other aspects but also asks for operation improvement among organizations in aspects of multilateral relation, cognition, culture and others.

\section{A. Inner mechanism}

\section{1) Construction of think tank in multiple dimensions}

Firstly, embeddedness theory emphasizes macro environment's effect on organizational behavior. Joint forces of all sectors of society should be efficiently used to broaden the sources of funds for think tank construction. In addition to expanding government's education input and completing relative tax policy, the fund can also be raised from enterprises, individuals, publishers and foundations, which means enterprises and individuals can provide contribution by donation, publishers by raising researchers' reward of result issue, other organizations by establishing foundations.

Secondly, embeddedness theory emphasizes the existence of multiple subjects from a medium perspective and the coordination and interaction among varied organizations are conducive to benefit maximization. As main market players, enterprises can abundant think tank's intelligence, while government, as the main investor and beneficial owner, determines the development, property and quality of the think tank. General education and vocational education should regard the two different aspects as the same thing. The former emphasizes the dissemination of academic knowledge, while the latter stresses the importance of the training of practical skill. If combines the two together, double benefit can be gained in the construction of vocational education think tank.
Thirdly, embeddedness theory also pays attention to bilateral cooperation between two organizations in micro level. It's only the first step building up cooperative relation since what really matters is the active maintenance of the relationship. Free flow of personnel of different filed should be encouraged instead of blind opposition to everything foreign and of being complacent and conservative. A professional platform should be established for sharing resources and information, satisfying demands of both parties. Additionally, basing on learning experience from each other, both parties are unleashed in creation and innovation.

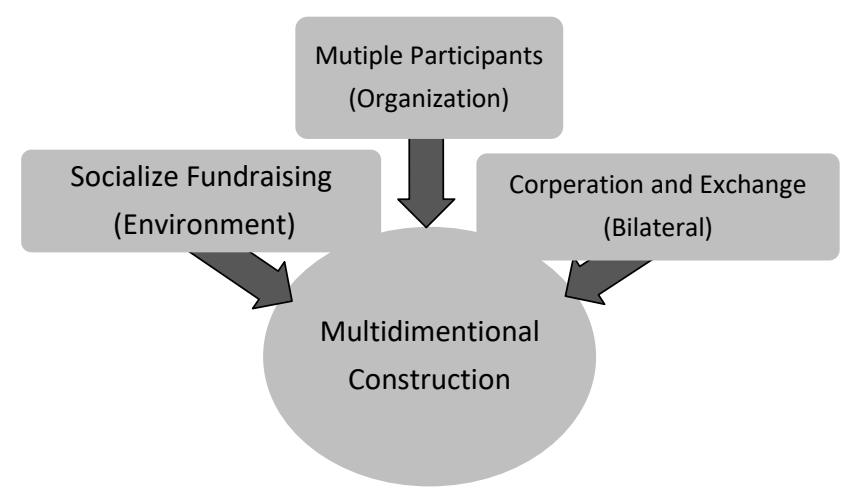

Fig. 2. Dimensional analysis on the construction of vocational education think tank

\section{2) All-around improvement of the construction of think} tank

Complicated relation network lays influence on organizational behavior by its content, intensity and duration, which is demonstrated in the relational dimension of embeddedness theory. As an important branch of the education sector and closely related to general, continuing and other types of education, vocational education is supposed to learn from and share information and resources with them so that its think tank will present the interdisciplinary trend.

As for cognition in embeddedness theory, it refers to long-developed group awareness and thoughts' guidance and restriction on the organization. Consensus, regulation, restriction and incentive system must be established, keeping the cooperation on track, to minimize conflict of interest, reduce the sense of strangeness and promote friendship, gradually cultivating the group's thoughts and sense of identity.

As for culture in embeddedness theory, it emphasizes the influence of traditional value, religion and belief, common faith and orthodox practice. It is an important measure to set up a private think tank for the diversification of education think tank. Although stated early with a great variety, an education think tanks in China are mostly run by governments and schools while private think tanks with local or school characteristics are in shortage, so that the promotion of private think tank is imperative. 


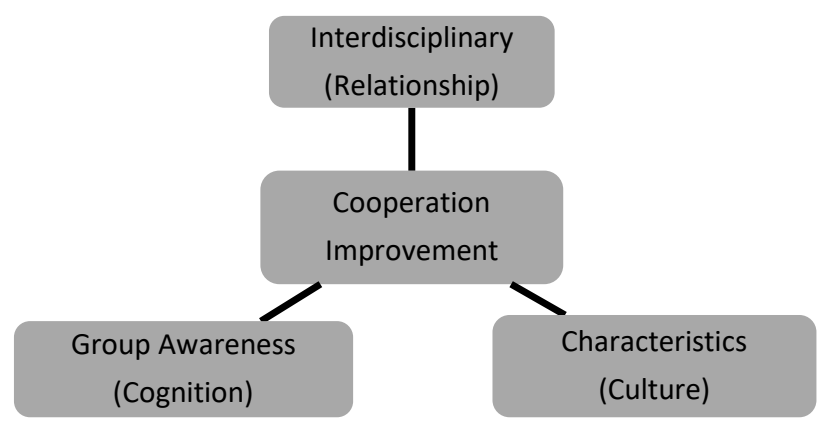

Fig. 3. Improvement of the construction of vocational education think tank

\section{B. Significance analysis}

Embeddedness theory provides the construction of vocational education think tank a fresh perspective in culture development, inner composition, society environment and groups' collaborative innovation.

1) Optimizing financing channel in externality for security

Based on environment embeddedness, multiple fundraising channels in all sectors of society must be explored for sufficient capital of the think tank construction. On the one side, resources integration can be improved with the help of enterprises, the public, the whole society and the nation. On the other side, the investment can be increased with tax reduction and financial support.

2) Promoting diverse cooperation among internal subjects for groups' collaborative innovation in a new way

Stressing the importance of interaction and coordination among multiple subjects, schools, enterprises, governments and the whole society are all encouraged to participate in the construction of vocational think tank. Not only basic research on education phenomena is conducted in theory dimension, but also empirical study is done on education issues at a practical level.

3) Emphasizing group identity from the respective of bilateral relation for new-form cooperation

Construction of vocational education think tank requires collaboration on condition that coherence, identity and regulation rules have been established in groups. It is referred in embeddedness theory that group thoughts and identity work as long-effect mechanism for group cooperation. As a consequence, only remodeling cooperative relationship among subjects can they realize win-win share and further develop cooperation with innovation.

4) Differentiation development in the respective of culture for think tank richness

Culture embeddedness suggests that inheritance, exchange and innovation of culture play significant roles in think tank's differentiation. The construction of vocational education think tank should cover both characteristics and diversification, in which power should be delegated to the lower levels, private think tank be put on the agenda, and boundary of discipline be shattered to enable issues to be coped with from different perspectives.

\section{NEW ROUTES}

New education think tank requires co-movement, diversification, independence, innovation and socialization. To realize this transformation, participants, communication mechanism, discipline dialogue, fundraising methods and organizational form are supposed to be improved in the construction of think tank.

\section{A. Completing the social fund system by broadening fundraising channel}

Joint forces of all sectors of society should be called to broaden fundraising channel. On the one side, governments can make tax preference or reduction policy, provide financial support for consulting enterprises, and arouse initiative of enterprises of different size to offer advice and suggestions. On the other side, the special fund can be set up so that vocational education think tank can got money specifically directed at them. In addition, research result issue reward, individual or enterprise donation can also play a part in socialized financing.

\section{B. Multiple subjects' cooperation to realize overall interaction, mutual benefit and win-win result}

Main participants in China's education think tank are collegiate scholars and professors, whose main work is teaching and education, so that they might be difficult with policy research and consulting [5]. Firstly, the government should eliminate worries and dilemma for think tank construction by providing policy guidance, financial support, supervision and safeguard. Secondly, enterprises should enhance occupational orientation of the think tank by offering help in the capital, equipment, technical personnel, research platform and other resources. Thirdly, research institutes and universities should provide professional research in trouble solving with large scientific research team and advanced instruments and equipment.

\section{Enhancing group identity by improving exchange and cooperation mechanism}

Favorable exchange and cooperation mechanism is the key to realize cooperation performance and efficiency. Firstly, to integrate personnel in the vocational education think tank. Based on bringing in and going out principle, free flow of talent resources among enterprises, governments, colleges and research institution should be established as well as varied research centers and study bases. Secondly, to set up share platform of information and resources and improve decision consulting mechanism. Governments should make information more transparent and openly, simplify research procedure and reduce the degree of difficulty. Thirdly, to establish a regulation system, in which effective restriction and incentive rules are built while evaluation criterion and accountability system are optimized.

\section{Shattering disciplinary boundary and building an interdisciplinary exchange platform}

Instead of self-imposed limitations, teachers, subject specialists and research workers in vocational school should enhance communication with practitioners of sociology, psychology and other fields to know their basic theory, research methods and academic frontier for new ideas to deal 
with their own issues. Meanwhile, when facing tough educational problems, experts and scholars of different discipline background can be invited to put heads together and to make countermeasure studies, providing analysis and solutions from different views.

\section{E. Enriching think tank variety and promoting private ones}

Firstly, to realize the independent development of private think tank and listen to the opinions and suggestion about it based on the principle of justice and equity. Secondly, to raise a special fund for the establishment and operation of private think tank and provide extra start-up funding. Thirdly, to break the monopoly of official education think tank and bring the private ones into research, injecting fresh vitality into the construction of vocational education think tank.

\section{CONCLUSION}

To sum up, construction of vocational education think tank based on embeddedness theory will not only overcome recent drawbacks but also can offer advice, guidance and suggestion of all-dimensional and multi-angle for the development of vocation education, predicting the future trend of new type think tank. However, the construction of education think tank is experiencing a dynamic development without a standard reference model which is universally applicable so that exploration on it would never stop. New construction path of time characteristics must be carved out according to the state-of-the-art and new requirement of the time.

\section{REFERENCES}

[1] Xia Zhengnong, Chen Zhili. Cihai[M]. Shanghai: Shanghai Lexicographical Publishing House, 2009.

[2] Richard Swedberg. Principles of Economic Sociology[M]. Translated by Zhou Changcheng et al. Beijing: China Renmin University Press, 2005.

[3] Zukin S, Dimaggio P. Structures of capital: the social organizations of the economy[M]. Cambridge, MA: Cambridge University Press, 1990 1-36.

[4] Yang Yubo, Li Beiyou, Li Shouwei. A Review of the Theory of Embeddability: From the Perspective of Universal Connection [J]. Shandong Social Sciences, 2014(03):172-176.

[5] Fang Ning. Influencing and Changing Society by Professional Research - Operation and Evaluation of Modern Think Tanks[J].China Development Observation,2012,(08).

[6] Zhuang Xizhen. On the Reforms of Local Government's Educational Governance Mode: From an Embedding Perspective[J]. Research in Education Development, 2008(21):7-10.

[7] Hao Ping. Improve the Service Level of Educational Think Tanks with the Guidance of Five Principles of Development [J]. Educational Research, 2016, 37(03):4-10.

[8] Wang Jianliang, Guo Wanting. Educational Think Tank Construction in China: Problems and Countermeasures[J].Research in Education Development, 2014, 34(09):1-6.

[9] Zhong Min. A Study on the Situation and Strategies of the Construction of the Educational Think Tank of University in Chongqing[D] Chongqing University, 2016.

[10] Granovetter M S. The impact of social structure on economic outcomes[J]. Journal of Economic Perspectives, 2005, 19(1):33-50. 